Article

\title{
Novel Coronavirus Infection (COVID-19) Related Thrombotic and Bleeding Complications in Critically Ill Patients: Experience from an Academic Medical Center
}

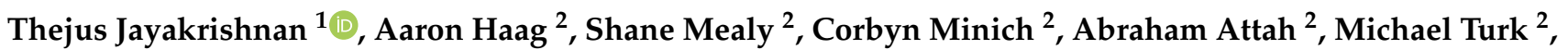 \\ Nada Alrifai ${ }^{2}$, Laith Alhuneafat ${ }^{2}$, Fadi Khoury ${ }^{2}$, Adeel Nasrullah ${ }^{2}$, Patrick Wedgeworth ${ }^{3}$, Melissa Mosley ${ }^{2}$, \\ Kirtivardan Vashistha ${ }^{2}$, Veli Bakalov ${ }^{2}$, Abhishek Chaturvedi ${ }^{4}$ and Swathi Sangli ${ }^{5, *}$
}

1 Department of Hematology and Medical Oncology, Cleveland Clinic, Cleveland, OH 44104, USA; thejus128@gmail.com

2 Department of Internal Medicine, Allegheny Health Network, Pittsburgh, PA 15222, USA; aaron.haag@ahn.org (A.H.); shane.mealy@ahn.org (S.M.); corbyn.minich2@ahn.org (C.M.); attah.abraham@ahn.org (A.A.); michael.turk@ahn.org (M.T.); nada.alrifai93@gmail.com (N.A.); laith.alhuneafat@ahn.org (L.A.); fadi.khoury93@gmail.com (F.K.); adeel.nasrullah@ahn.org (A.N.); Melissa.Mosley@ahn.org (M.M.); Kirtivardan.Vashistha@ahn.org (K.V.); Veli.Bakalov@ahn.org (V.B.)

3 Department of Bioinformatics, University of Washington, Seattle, WA 98195, USA; james.wedgeworth@gmail.com

4 Department of Cardiology, Virginia Commonwealth University, Richmond, VA 23284, USA; abhishek.chaturvedi2391@gmail.com

5 Department of Pulmonary and Critical Care Medicine, Allegheny Health Network, Pittsburgh, PA 15222, USA

check for updates

Citation: Novel Coronavirus Infection (COVID-19) Related Thrombotic and Bleeding Complications in Critically Ill Patients: Experience from an Academic Medical Center. J. Clin. Med. 2021, 10, 5652. https:// doi.org/10.3390/jcm10235652

Academic Editor:

Ferdinando Mannello

Received: 9 November 2021

Accepted: 23 November 2021

Published: 30 November 2021

Publisher's Note: MDPI stays neutral with regard to jurisdictional claims in published maps and institutional affiliations.

Copyright: (C) 2021 by the authors. Licensee MDPI, Basel, Switzerland. This article is an open access article distributed under the terms and conditions of the Creative Commons Attribution (CC BY) license (https:/ / creativecommons.org/licenses/by/ $4.0 /$ )

* Correspondence: swathi.sangli@ahn.org; Tel.: +1-412-578-4226

Abstract: Introduction: Thrombosis and bleeding are recognized complications of the novel coronavirus infection (COVID-19), with a higher incidence described particularly in the critically ill. Methods: A retrospective review of COVID-19 patients admitted to our intensive care units (ICU) between 1 January 2020 and 31 December 2020 was performed. Primary outcomes included clinically significant thrombotic and bleeding events (according to the ISTH definition) in the ICU. Secondary outcomes included mortality vis-a-vis the type of anticoagulation. Results: The cohort included 144 consecutive COVID-19 patients with a median age of 64 years (IQR 54.5-75). The majority were male $(85(59.0 \%))$ and Caucasian $(90(62.5 \%))$ with a median BMI of $30.5 \mathrm{~kg} / \mathrm{m}^{2}$ (IQR 25.7-36.1). The median APACHE score at admission to the ICU was 12.5 (IQR 9.5-22). The coagulation parameters at admission were a d-dimer level of $109.2 \mathrm{mg} / \mathrm{mL}$, a platelet count of $217.5 \mathrm{k} / \mathrm{mcl}$, and an INR of 1.4. The anticoagulation strategy at admission included prophylactic anticoagulation for 97 (67.4\%) patients and therapeutic anticoagulation for $35(24.3 \%)$ patients, while $12(8.3 \%)$ patients received no anticoagulation. A total of 29 patients $(20.1 \%)$ suffered from thrombotic or major bleeding complications. These included 17 thrombus events $(11.8 \%)-8$ while on prophylactic anticoagulation (7 regular dose and 1 intermediate dose) and 9 while on therapeutic anticoagulation ( $p$-value $=0.02$ - and 19 major bleeding events (13.2\%) (4 on no anticoagulation, 7 on prophylactic (6 regular dose and 1 intermediate dose), and 8 on therapeutic anticoagulation $(p$-value $=0.02))$. A higher thrombosis risk among patients who received remdesivir $(18.8 \%$ vs. $5.3 \%(p$-value $=0.01))$ and convalescent serum $(17.3 \%$ vs. $5.8 \%(p$-value $=0.03 \%))$ was noted, but no association with baseline characteristics (age, sex, race, comorbidity), coagulation parameters, or treatments (steroids, mechanical ventilation) could be identified. There were 10 pulmonary embolism cases $(6.9 \%)$. A total of $99(68.8 \%)$ patients were intubated, and 66 patients $(45.8 \%)$ died. Mortality was higher, but not statistically significant, in patients with thrombotic or bleeding complications-58.6\% vs. $42.6 \%$ ( $p$-value $=0.12$ ) —and higher in the bleeding $(21.2 \%)$ vs. thrombus group $(12.1 \%), p$-value $=0.06$. It did not significantly differ according to the type of anticoagulation used or the coagulation parameters. Conclusions: This study describes a high incidence of thrombotic and bleeding complications among critically ill COVID-19 patients. The findings of thrombotic events in patients on anticoagulation and major bleeding events in patients on no or prophylactic anticoagulation pose a challenging clinical dilemma in the issue of anticoagulation for COVID-19 patients. The questions raised by this study and previous literature on 
this subject demonstrate that the role of anticoagulation in COVID-19 patients is worthy of further investigation.

Keywords: COVID19; SARS-CoV-2; ICU; thrombosis; bleeding mortality

\section{Introduction}

Since its emergence, the novel coronavirus infection (COVID-19) has remained a global health crisis and continues to impose significant social, psychological, and logistical burdens on individuals and health care systems [1]. Robust research has resulted in a better understanding of the natural history of the disease, the characteristics of the patients, and the predictors of outcomes. Studies suggest that up to $6 \%$ of COVID-19 patients in the US require ICU admission and experience the highest rate of mortality [2]. COVID-19-associated thrombotic and bleeding complications are increasingly recognized as complications of the novel coronavirus (COVID-19), with a higher incidence described particularly in the critically ill. This is described to occur from a cascade of immune responses, which lead to hyperinflammation, endotheliopathy, deranged hemostasis, and fibrinolysis, resulting in hypercoagulability and severe thromboembolic complications $[3,4]$. These patients exhibit a spectrum of microvascular and macrovascular, arterial, and venous thrombotic complications, including deep vein thrombosis, pulmonary embolism, arterial thrombosis, myocardial infarction, and even large-vessel ischemic strokes. Bleeding is less commonly reported compared to thrombosis $[5,6]$.

The incidence of venous thromboembolism upon coronavirus infection significantly differs depending on the variable ultrasound screening practices, ranging from as low as $2 \%$ to as high as $69 \%$. Regardless, the incidence of thrombotic complications is higher in patients admitted to intensive care units (ICU) [7-15]. However, COVID-19-associated thrombotic complications are highly associated with a worse prognosis [16]. The current guidelines are primarily based on the interim results of three major clinical trials [17-20]. Further studies would help us to determine the definitive impact, safety, and efficacy of the use of intermediate- compared to full-dose therapeutic anticoagulation to prevent thrombotic complications. With the potential bleeding risk in the critically ill and in the absence of established indications for anticoagulation, determining the effective anticoagulation dose is complex.

Allegheny Health Network (AHN) is one of the big consortiums of academic (urban) and non-academic (rural) hospitals in Western Pennsylvania. It has been at the forefront of the battle against COVID-19 in Pennsylvania [21-23]. Here, we have sought to describe COVID-19-associated thrombotic and major bleeding in patients admitted to our ICU and assess the associated risk factors that would help in the risk stratification of patients and assist in determining our anticoagulation strategies going forward.

\section{Methods}

\subsection{Study Population}

We conducted a retrospective study of all COVID-19 patients consecutively admitted to the AHN's intensive care units (ICU) between 1 January 2020 and 31 December 2020. All the patients were diagnosed with COVID-19 by real-time polymerase chain reaction (RT-PCR) tests via nasal swabs. The cohort included patients transferred to ICU for the escalation of care and direct admissions from the emergency department. For patients with readmissions, only the index hospitalization due to COVID-19 is included in this study. The independent clinical judgment of providers determined the patients' disposition to ICU. The severity of illness was determined by the sequential organ failure assessment (SOFA) and the acute physiology and chronic health evaluation 2 (APACHE 2) scoring system. The study excluded patients previously on therapeutic anticoagulation due to arrhythmias or prior history of thrombus. 
The AHN institutional review board committee approved the study and waived the need for informed consent. Deidentified data was collected from the AHN electronic health record system (Epic) and included patient demographics, medical history, home medications, clinical presentation characteristics, and treatment strategies. A Charlson Comorbidity Index (CCI) was also calculated for analysis.

\subsection{Outcomes Analyzed Were as Follows}

\subsubsection{Primary Outcomes}

1. Clinically significant thrombosis of the different types, including DVT, hepatic vein thrombosis, and arterial thrombosis.

2. Clinically significant bleeding of the different types as defined by the ISTH definition of having a symptomatic presentation and (1) fatal bleeding and/or (2) bleeding in a critical area or organ (such as intracranial, intraspinal, intraocular, retroperitoneal, intra-articular, pericardial, or intramuscular bleeding with compartment syndrome) and/or (3) bleeding causing a fall in hemoglobin level to $20 \mathrm{~g} \mathrm{~L}^{-1}\left(1.24 \mathrm{mmol} \mathrm{L}^{-1}\right)$ or less or leading to the transfusion of two or more units of whole blood or red cells [24].

\subsubsection{Secondary Outcomes}

1. Mortality.

2. Correlative analysis of development of thrombus with the type of anticoagulation.

Our academic medical center, comprising a multidisciplinary team, developed a treatment algorithm based on a review of several early published studies at the beginning of the pandemic. Please refer to Figure 1 for our treatment algorithm and dosing strategies. We utilized a physician-based risk stratification of a patient's bleeding risk on admission, which included various coagulation parameters and imaging studies. Prophylactic anticoagulation was indicated for all patient populations with low bleeding risk and low-risk COVID-19 disease, unless the patients had a contraindication, were previously on therapeutic anticoagulation for a specific etiology, or had a history of heparin-induced thrombocytopenia. In contrast, those with high-risk COVID-19 disease requiring higher respiratory support ( $>6 \mathrm{~L} \mathrm{NC}$ ) were recommended to undergo baseline imaging to assess them for thrombosis. However, some of the patients enrolled during the early periods of the study did not undergo baseline imaging. Patients with evidence of thrombosis were treated with therapeutic anticoagulation, and those without VTE were treated with an intermediate-dosed anticoagulation strategy. Since many patients transitioned between anticoagulants depending on their clinical status, the anticoagulant regimen at admission to the ICU and during the thrombotic or bleeding event were used in the analysis.

\subsection{Statistical Analysis}

Categorical outcomes are described in percentages and continuous variables with medians and interquartile ranges (IQR). Group comparisons of proportions were performed using the $\chi^{2}$ test, while continuous variables were compared using the multiple analysis of variance (MANOVA) test or the Student's $t$-test as appropriate. Univariate logistic regression analysis for mortality was performed for variables with at least 20 observations. Multivariate regression was not performed due to the small sample size and established interactions amongst different variables resulting in a model that may not add meaningful additional information to the existing results. Statistical tests were 2-tailed and statistical significance was defined as a $p$-value $\leq 0.05$. Analyses were performed using Stata version 15.1 (Stata Corp., College Station, TX, USA). Since the analyses were not adjusted for multiple comparisons and were prone to type-I error, the findings should be interpreted as exploratory. 


\begin{tabular}{|c|c|c|c|}
\hline \multicolumn{4}{|c|}{$\begin{array}{l}\text { COVID } 19 \text { Admission } \\
\text { Order baseline CBC, PT, PTT, D-Dimer and Fibrinogen levels }\end{array}$} \\
\hline \multicolumn{2}{|r|}{ Prophylactic Dose } & Intermediate Dose & Therapeutic Dose \\
\hline \multicolumn{2}{|c|}{$\begin{array}{l}\text { All admitted patients and PIt > } 25 \mathrm{k} \text {, Fib > } 60 \mathrm{mg} / \mathrm{dl} \\
\text { thromboprophylaxis with Weight based } \mathrm{LMWH}(\mathrm{CrCl}> \\
\text { 30) or UFH }(\mathrm{CrCl}<30)\end{array}$} & $\begin{array}{l}\text { Patients without thrombosis with D Dimer > } 3 \text { ug/ml or > } \\
6 x \text { ULN and Plt }>50 \mathrm{k}, \mathrm{Fib}>100 \mathrm{mg} / \mathrm{dl} \\
\text { intermediate dose LMWH ( see dosing below) } \\
\text { Obtain baseline VTE imaging as able }\end{array}$ & $\begin{array}{l}\text { Patients with new proven VTE or on therapeutic } \\
\text { anticoagulation prior to admission and Plt }>50 \mathrm{k} \text {, } \\
\text { Fib }>100 \mathrm{mg} / \mathrm{dl} \\
\mathrm{Cr} \mathrm{Cl}>30 \text { - LMWH } 1.5 \mathrm{mg} / \mathrm{kg} \text { daily or } 1 \mathrm{mg} / \mathrm{kg} \text { bid } \\
\mathrm{Cr} \mathrm{Cl}<30 \text { - UFH gtt ( Use anti fac Xa nomogram ) }\end{array}$ \\
\hline \multicolumn{2}{|c|}{ If $\mathrm{CrCl}>30$ use enoxaparin at following dose } & \multirow{7}{*}{$\begin{array}{l}\mathrm{Cr} C l>30 \text { - Enoxaparin } 1 \mathrm{mg} / \mathrm{kg} \text { daily or } 0.5 \mathrm{mg} / \mathrm{kg} \text { bid } \\
\mathrm{Cr} \mathrm{Cl} 15 \text { - } 30 \text { - Enoxaparin } 0.5 \mathrm{mg} / \mathrm{kg} \text { daily } \\
\mathrm{OR} \\
\mathrm{ICU} \text { pts consider UFH gtt using low intensity anti Xa } \\
\text { nomogram to target anti fac Xa (0.3-0.55) } \\
\mathrm{For} \mathrm{CrCl}<15 \text { or on dialysis maintain on prophylactic } \\
\text { UFH } \\
\text { Monitor with LMWH anti Factor Xa level } 3 \text { times a week } \\
\text { for patients with weight > } 120 \mathrm{~kg} \text {, CrCl } 15-30 \text { and at } \\
\text { physician discretion for any significant changes in renal } \\
\text { function. } \\
\text { Target Level: } 0.4-0.6 \text {. Level to be drawn } 4-6 \text { hours } \\
\text { after LMWH dose. }\end{array}$} & \multirow{5}{*}{$\begin{array}{l}\text { Monitor with LMWH anti Factor Xa level } 3 \text { times a week } \\
\text { for patients with weight > } 120 \mathrm{~kg} \text {, and at physician } \\
\text { discretion for any significant changes in renal function. } \\
\text { Target Level : } 0.7-1.0 \text { Level to be drawn } 4-6 \text { hours } \\
\text { after LMWH dose. }\end{array}$} \\
\hline \begin{tabular}{|l|} 
Patient weight \\
$<60 \mathrm{Kg}$ \\
$600 \mathrm{Kg}$ \\
\end{tabular} & \begin{tabular}{|l|}
\multicolumn{1}{|c|}{ Dose } \\
$30 \mathrm{mg}$ daily \\
$40 \mathrm{mg}$ daily
\end{tabular} & & \\
\hline $100-140 \mathrm{~kg}$ & $\begin{array}{l}40 \mathrm{mg} \text { dally } \\
30 \mathrm{mg} \text { every } 12 \text { hours }\end{array}$ & & \\
\hline \begin{tabular}{|l}
$140-160 \mathrm{~kg}$ \\
$>160 \mathrm{~kg}$ \\
\end{tabular} & $\begin{array}{l}40 \mathrm{mg} \text { every } 12 \text { hours } \\
60 \mathrm{mg} \text { every } 12 \text { huurs }\end{array}$ & & \\
\hline \multicolumn{2}{|c|}{ If $\mathrm{CrCl}<30$ use unfractionated heparin } & & \\
\hline \begin{tabular}{|l|} 
Patient weight \\
$<60 \mathrm{Kg}$ \\
$60-120 \mathrm{Kg}$ \\
$>120 \mathrm{~kg}$ \\
\end{tabular} & \begin{tabular}{|l} 
Dose \\
5000 U every 12 hours \\
5000 U every 8 hours \\
7500 U every 8 hours
\end{tabular} & & \multirow{2}{*}{$\begin{array}{l}\text { There are no clear consensus guidelines at this } \\
\text { time for empiric use of therapeutic doses of } \\
\text { anticoagulation. } \\
\text { This can be considered at the discretion of } \\
\text { treating physician. Refer to \# } 4 \text { in the document }\end{array}$} \\
\hline \multicolumn{2}{|c|}{$\begin{array}{l}\text { For patients with } \mathrm{h} / \mathrm{o} \mathrm{HIT} \text { and } \mathrm{CrCl}>30 \text { use: } \\
\text { Fondaparinux } 2.5 \mathrm{mg} \text { daily. }\end{array}$} & & \\
\hline \multicolumn{4}{|c|}{ Always assess risk factors for bleeding before starting or increasing dose of anticoagulation } \\
\hline \multicolumn{4}{|c|}{$\begin{array}{l}\text { Complete } 3 \text { months total of anticoagulation at discharge using a direct oral anticoagulant if therapeutic anticoagulation was used during admission. } \\
\text { In others, consider post discharge thromboprophylaxis with Rivaroxaban } 10 \mathrm{mg} \text { qd or Apixaban } 2.5 \mathrm{mg} \text { bid for } 30 \text { days in patients who have risk factors - age over } 75 \text {, Obese, active cancer, } \mathrm{d} \text { dimer } \\
2 \times \text { ULN before discharge. Refer to } \# 5 \text { in the document for details }\end{array}$} \\
\hline
\end{tabular}

Figure 1. Institutional COVID-19 anticoagulation guideline at Allegheny Health Network.

\section{Results}

\subsection{Characteristics of Patients Admitted to ICU}

The cohort included 144 consecutive COVID-19 patients with a median age of 64 years (IQR 54.5-75). The characteristics are outlined in Table 1. The majority were male (85 $(59.0 \%))$ and Caucasian $\left(90(62.5 \%)\right.$ ) with a median body mass index (BMI) of $30.5 \mathrm{~kg} / \mathrm{m}^{2}$ (IQR 25.7-36.1). The median APACHE score at admission to the ICU was 12.5 (IQR 9.5-22) and the median CCI score was 1 (IQR 0-3). The coagulation parameters at admission to the ICU were a d-dimer level of $1.5 \mathrm{mg} / \mathrm{mL}$ (IQR 1.1-4.7), a platelet count of $217.5 \mathrm{k} / \mathrm{mcl}$ (IQR 150-288), and an international normalized ratio (INR) of 1.4 (IQR 1.1-1.3).

Table 1. Characteristics of patients admitted to the ICU with COVID-19.

\begin{tabular}{cc}
\hline Characteristics $(n=\mathbf{1 4 4})$ & Percentage or Median (IQR) \\
\hline Age (in years) & $64(54.5-75)$ \\
Gender & $85(59.0 \%)$ \\
Male & $59(41.0)$ \\
Female & \\
Race & $90(62.5 \%)$ \\
Non-Hispanic White & $36(25.0 \%)$ \\
Non-Hispanic Black & $18(12.5 \%)$ \\
Others & $102(70.8 \%)$ \\
Comorbidities & $76(52.8 \%)$ \\
Cardiovascular ${ }^{\text {a }}$ & $57(39.6 \%)$ \\
Obesity (BMI > 30 kg/m $\left.{ }^{2}\right)$ & $18(12.5 \%)$ \\
Diabetes & $24(16.7 \%)$ \\
Chronic obstructive pulmonary disease & $1(0-3)$ \\
Renal ${ }^{\text {C }}$ & \\
CCI & $1.5 \mathrm{mg} / \mathrm{mL}(1.1-4.7)$ \\
d-dimer & $217.5 \mathrm{k} / \mathrm{mcl}^{(150-288)}$ \\
Platelets & $1.4(1.1-1.3)$ \\
International normalized ratio (INR) & $12.5(9.5-22)$ \\
ICU Admission Severity of Illness &
\end{tabular}


Table 1. Cont.

\begin{tabular}{cc}
\hline Characteristics $(\boldsymbol{n}=\mathbf{1 4 4})$ & Percentage or Median (IQR) \\
\hline Treatment Strategies & \\
Mechanical ventilation & $99(68.8 \%)$ \\
Pressors & $80(55.6 \%)$ \\
Neuromuscular blockade use & $49(35.0 \%)$ \\
Steroids & $46(31.9 \%)$ \\
Renal replacement therapy & $20(13.8 \%)$ \\
Mechanical circulatory support & $7(4.9 \%)$ \\
Convalascent plasma & $75(52.1 \%)$ \\
Remdesivir & $69(47.9 \%)$ \\
\hline
\end{tabular}

$\overline{\mathrm{IQR}}=$ interquartile range, $\mathrm{BMI}=$ body mass index, $\mathrm{CCI}=$ Charlson Comorbidity Index, APACHE $=$ acute physiology and chronic health evaluation. ${ }^{a}$ Documented history of coronary artery disease or hypertension. $\mathrm{b}$ Documented history of chronic kidney disease.

\subsection{ICU Treatments}

Following admission to the ICU, $99(68.8 \%)$ patients required mechanical ventilation, $80(55.6 \%)$ patients required vasopressor support, $20(13.8 \%)$ patients needed renal replacement therapy, and $7(4.9 \%)$ patients needed mechanical circulatory support. Pharmacological treatment for COVID-19 and respiratory failure management included steroids in $46(31.9 \%)$ patients, remdesivir in $69(47.9 \%)$ patients, neuromuscular paralysis in 49 (35.0\%) patients, and convalescent plasma in $75(52.1 \%)$ patients.

\subsection{Thrombotic or Bleeding Complications}

The anticoagulation strategy at admission included prophylactic anticoagulation for $97(67.4 \%)$ patients and therapeutic anticoagulation for $35(24.3 \%)$ patients, while $12(8.3 \%)$ patients received no anticoagulation. The reasons for anticoagulation may have been high suspicion of a DVT/PE by the treatment team prior to transfer to the ICU or new arrhythmias. The exact reason for the anticoagulation prior to transfer to the ICU, and its timing, was not collected during data extraction. A total of $29(20.1 \%)$ patients suffered from thrombus or major bleeding. These included 17 new thrombus events $(11.8 \%)(8$ while on prophylactic anticoagulation (7 regular dose and 1 intermediate dose) vs. 9 on therapeutic anticoagulation ( $p$-value $=0.02)$ ) and 19 major bleeding $(13.2 \%)-4$ on no anticoagulation vs. 7 on prophylactic ( 6 regular dose and 1 intermediate dose) vs. 8 on therapeutic anticoagulation $(p$-value $=0.02)$. There were patients who had both thrombotic and bleeding complications. There were 10 pulmonary embolism cases (6.9\%). The outcomes are summarized in Table 2.

Table 2. Outcomes of patients admitted to ICU stratified by the type of anticoagulation.

\begin{tabular}{|c|c|c|c|c|c|}
\hline & $\begin{array}{c}\text { Prophylactic } \\
\text { Anticoagulation }\end{array}$ & $\begin{array}{l}\text { Intermediate Dose } \\
\text { Anticoagulation }\end{array}$ & $\begin{array}{c}\text { Therapeutic } \\
\text { Anticoagulation }\end{array}$ & None & Total \\
\hline Number of patients & $89(61.8 \%)$ & $8(5.6 \%)$ & $35(24.3 \%)$ & $12(8.3 \%)$ & 144 \\
\hline $\begin{array}{l}\text { Thrombotic } \\
\text { Complications }\end{array}$ & 7 & 1 & 9 & 0 & $17(11.8 \%)$ \\
\hline $\begin{array}{l}\text { Major Bleeding } \\
\text { Complications }\end{array}$ & 6 & 1 & 8 & 4 & $19(13.2 \%)$ \\
\hline Death & $36(54.6 \%)$ & $6(9.1 \%)$ & $17(25.8 \%)$ & $7(12 \%)$ & $66(45.8 \%)$ \\
\hline
\end{tabular}

Higher thrombosis risk among patients who received remdesivir $(18.8 \%$ vs. $5.3 \%$ $(p$-value $=0.01))$ and convalescent serum $(17.3 \%$ vs. $5.8 \%(p$-value $=0.03))$ were noted. No other associations were noted, including baseline characteristics-gender (male $14 \%$ vs. female $8.5 \%, p$-value $=0.3)$, age $(p$-value $=0.88)$, different races $(p$-value $=0.22)$, comorbidity index $(p$-value $=0.52)$, APACHE score $(p$-value $=0.79)$, BMI $(p$-value $=0.72)$; coagulation 
parameters-d-dimer $(p$-value $=0.58)$, platelets $(p$-value $=0.22), \operatorname{INR}(p$-value $=0.06)$; ICU treatments-steroid use vs. none $(10.9 \%$ vs. $12.2 \%, p$-value $=0.81)$, mechanical ventilation vs. none $(14.1 \%$ vs. $6.7 \%, p$-value $=0.20)$, mechanical circulatory support vs. none $(28.6 \%$ vs. $11.0 \%, p$-value $=0.16)$, neuromuscular blockade vs. none $(16.3 \%$ vs. $9.9 \%$, $p$-value $=$ $0.27)$, or the use of pressors vs. none $(16.3 \%$ vs. $6.3 \%$, $p$-value $=0.07)$.

\subsection{ICU Complications and Mortality}

Of the entire cohort, 66 patients $(45.8 \%)$ died. Mortality was higher, but not statistically significant, in patients with thrombotic or bleeding complications $(58.6 \%$ vs. $42.6 \%(p$-value $=0.12))$ and higher in the bleeding $(21.2 \%)$ vs. the thrombus group $(12.1 \%)$, $p$-value $=0.06$. It did not significantly differ by the type of anticoagulation $(p$-value $=0.57)$ or according to the coagulation parameters.

\section{Discussion}

Our study suggests that COVID-19 among critically ill patients is associated with a high incidence of complications from the derangement of the coagulation system, and this pertains to both thrombotic and bleeding complications.

While the underlying mechanisms are yet to be clearly elucidated, the current literature elaborating its pathophysiology suggests that the viral infection, with its uninhibited replication, results in endothelial dysfunction and consequently systemic hyperinflammation. The latter is believed to precipitate thrombin generation, high levels of d-dimer, fibrin degradation products, thrombocytopenia, and prolonged clotting times [25]. Studies using viscoelastic methods on these patients have also demonstrated hypercoagulability and fibrinolysis shutdown even for thromboprophylaxis that was deemed appropriate [4]. Furthermore, endothelial dysfunction is known to cause the characteristic procoagulant response with frequently noted micro and macrothrombi, which correlates directly with fibrin elevation and, in severe cases, the elevation of inflammatory cytokines, including tumor necrosis factor, IL-1, and IL-6 [25]. The presence of some of these markers by itself is associated with poor COVID-19 outcomes, possibly with a contribution from the dysfunction of the coagulation system [6,26].

Our study noted a high rate of thrombotic events in critically ill patients, which is consistent with most of the reported evidence thus far [6,27-29]. However, in a recent multicenter cohort study in the US among COVID-19 patients [5], the incidence of thrombotic events in COVID-19 patients was found to be lower than previous evidence and, indeed, the findings of our study suggest. Notably, our patients developed thrombotic events despite being treated with prophylactic or therapeutic anticoagulation. A higher thrombosis risk was also seen among patients receiving remdesivir and convalescent plasma, an association that has not been reported previously [30,31]. This should be interpreted within the limitations of the present study and evaluated in future studies.

On the other end of the spectrum, initial studies demonstrated severe bleeding events at an increased rate among hospitalized patients on therapeutic anticoagulation compared to patients receiving prophylactic AC or no AC [9,32]. Our study noted a higher bleeding incidence than in the recently reported literature, and half of those with major bleeding events were on no anticoagulation or only on the thrombo-prophylactic dose $[5,18]$. The timing of the occurrence of these complications during the patient's hospitalization has been previously reported to have a biphasic distribution [33]. Major bleeding events occurred later in the hospital stay and followed a decrease in fibrinogen and d-dimer several days prior, although we could not corroborate this distribution [33]. This high bleeding incidence further reinforces the complicated nature of the effect of COVID-19 infection on the coagulation system, regardless of the anticoagulation dose, and underlines the need for additional studies to identify risk factors for patients who succumb to these complications.

The spectrum of coagulation-system dysfunction associated with COVID-19 infection raises several questions about the timing and efficacy of anticoagulation strategies and 
the need to identify different phenotypes to enable risk stratification. Indeed, several studies have examined the effect of empiric anticoagulation (AC) on hospitalized COVID19 patients. Based on the initial limited observational studies reported, the American Society of Hematology recommended the use of thromboprophylactic-dose rather than intermediate- or therapeutic-dose anticoagulation in ICU patients and other hospitalized patients $[5,9,17,32]$. However, other investigators have demonstrated the benefits of the initiation of an early therapeutic dose of AC compared with no AC, with a $27 \%$ decrease observed in 30-day mortality without any increased risk of severe bleeding events [34]. This was contradicted by a large open-label multiplatform controlled trial that studied the use of therapeutic anticoagulation as an initial strategy in critically ill patients and demonstrated no survival benefit amongst the therapeutic AC group in comparison with the thromboprophylaxis group [35]. Interestingly, the same study demonstrated the survival benefit of hospital discharge along with decreased requirements for cardiorespiratory support among noncritically ill patients who were put on therapeutic anticoagulation compared to the thromboprophylaxis group [36]. The postulated reason behind this benefit appears to be that the severely ill patients in the ICU may have significantly advanced derangements in coagulation that are no longer amenable to antithrombin inhibition with heparin, while moderately ill patients might have derangements that are less resistant and still amenable to heparin [37]. With the current level of evidence, it is clear that the debate about the appropriate anticoagulation strategy is likely to continue despite this multiplatform trial, especially given the limitations noted in the study.

The limitations of our study include those inherent to the retrospective study design, such as recall biases, indication biases, and the presence of uncharacterized confounding factors. These limitations can be overcome only through prospective cohort studies, which we recommend. While a multivariate regression analysis could have helped us to identify how various factors impacted mortality in a combined model, it was not performed due to the complexity of the resultant model, which failed to add to the presented results significantly. Concerns may also include the potential lack of power and small number of events, which were factors beyond our control given the predefined eligibility criteria. We plan to revisit the results in the future with a larger, updated dataset to address some of these limitations. The follow-up was limited to the inpatient hospital stay and did not capture complications or readmission post-discharge. The data included are from two different hospitals, and variations may exist due to the practice and population patterns of the individual hospitals. Additionally, the use of viscoelastic methods to identify patients at risk for coagulopathy is also being investigated [4].

\section{Conclusions}

This study describes a high incidence of thrombotic and bleeding complications among critically ill COVID-19 patients. The findings of thrombotic events in patients on anticoagulation and major bleeding events in patients on no or prophylactic anticoagulation pose a challenging clinical dilemma in the issue of anticoagulation for COVID-19 patients. The questions raised by this study and previous research on the subject demonstrate that the role of anticoagulation in COVID-19 patients is worthy of further investigation.

Author Contributions: Study concept and design: All authors; Data collection: T.J., A.H., S.M., C.M., A.A., M.T., N.A., L.A., F.K., A.N., P.W., M.M. and K.V.; Analysis and interpretation of data: T.J., S.S.; Drafting of the manuscript: T.J., A.H., S.M., C.M., A.A., M.T., N.A., L.A., F.K., A.N., P.W., M.M., K.V., V.B., A.C. and S.S.; Critical revision of the manuscript for important intellectual content: All authors; Administrative, technical, or material support: S.S. All authors have read and agreed to the published version of the manuscript.

Funding: This research received no external funding.

Institutional Review Board Statement: The study was exempt from institutional review board oversight.

Informed Consent Statement: Patient consent was waived as there was no direct patient involvement. 
Data Availability Statement: All authors had full access to all the data in the study. We take full responsibility for the integrity of the data and the accuracy of the analysis as well as sharing the data with any interested investigators.

Acknowledgments: Nicole Wilson, Matt Goodwin, Mario Castagnaro, Anastasios Kapetanos.

Conflicts of Interest: The authors declare no conflict of interest.

\section{References}

1. Richardson, S.; Hirsch, J.S.; Narasimhan, M.; Crawford, J.M.; McGinn, T.; Davidson, K.W.; Barnaby, D.P.; Becker, L.B.; Chelico, J.D.; Cohen, S.L.; et al. Presenting Characteristics, Comorbidities, and Outcomes Among 5700 Patients Hospitalized With COVID-19 in the New York City Area. JAMA 2020. [CrossRef] [PubMed]

2. CDC Coronavirus Disease 2019 (COVID-19). Available online: https://www.cdc.gov/coronavirus/2019-ncov/need-extraprecautions / racial-ethnic-minorities.html (accessed on 6 May 2020).

3. Leentjens, J.; van Haaps, T.F.; Wessels, P.F.; Schutgens, R.E.G.; Middeldorp, S. COVID-19-associated coagulopathy and antithrombotic agents-Lessons after 1 year. Lancet Haematol. 2021. [CrossRef]

4. Słomka, A.; Kowalewski, M.; Żekanowska, E. Hemostasis in Coronavirus Disease 2019-Lesson from Viscoelastic Methods: A Systematic Review. Thromb. Haemost. 2021, 121, 1181-1192. [CrossRef]

5. Al-Samkari, H.; Gupta, S.; Leaf, R.K.; Wang, W.; Rosovsky, R.P.; Brenner, S.K.; Hayek, S.S.; Berlin, H.; Kapoor, R.; Shaefi, S.; et al. Thrombosis, Bleeding, and the Observational Effect of Early Therapeutic Anticoagulation on Survival in Critically Ill Patients With COVID-19. Ann. Intern. Med. 2021, 174, 622-632. [CrossRef]

6. Al-Samkari, H.; Karp Leaf, R.S.; Dzik, W.H.; Carlson, J.C.T.; Fogerty, A.E.; Waheed, A.; Goodarzi, K.; Bendapudi, P.K.; Bornikova, L.; Gupta, S.; et al. COVID-19 and coagulation: Bleeding and thrombotic manifestations of SARS-CoV-2 infection. Blood 2020, 136, 489-500. [CrossRef] [PubMed]

7. Sakr, Y.; Giovini, M.; Leone, M.; Pizzilli, G.; Kortgen, A.; Bauer, M.; Tonetti, T.; Duclos, G.; Zieleskiewicz, L.; Buschbeck, S.; et al. Pulmonary embolism in patients with coronavirus disease-2019 (COVID-19) pneumonia: A narrative review. Ann. Intensive Care 2020, 10, 124. [CrossRef] [PubMed]

8. McBane, R.D.; Torres Roldan, V.D.; Niven, A.S.; Pruthi, R.K.; Franco, P.M.; Linderbaum, J.A.; Casanegra, A.I.; Oyen, L.J.; Houghton, D.E.; Marshall, A.L.; et al. Anticoagulation in COVID-19: A Systematic Review, Meta-analysis, and Rapid Guidance From Mayo Clinic. Mayo Clin. Proc. 2020, 95, 2467-2486. [CrossRef] [PubMed]

9. Ionescu, F.; Jaiyesimi, I.; Petrescu, I.; Lawler, P.R.; Castillo, E.; Munoz-Maldonado, Y.; Imam, Z.; Narasimhan, M.; Abbas, A.E.; Konde, A.; et al. Association of anticoagulation dose and survival in hospitalized COVID-19 patients: A retrospective propensity score-weighted analysis. Eur. J. Haematol. 2021, 106, 165-174. [CrossRef] [PubMed]

10. Klok, F.A.; Kruip, M.J.H.A.; van der Meer, N.J.M.; Arbous, M.S.; Gommers, D.A.M.; Kant, K.M.; Kaptein, F.H.J.; van Paassen, J.; Stals, M.A.M.; Huisman, M.V.; et al. Incidence of thrombotic complications in critically ill ICU patients with COVID-19. Thromb. Res. 2020, 191, 145-147. [CrossRef] [PubMed]

11. Klok, F.A.; Kruip, M.J.H.A.; van der Meer, N.J.M.; Arbous, M.S.; Gommers, D.; Kant, K.M.; Kaptein, F.H.J.; van Paassen, J.; Stals, M.A.M.; Huisman, M.V.; et al. Confirmation of the high cumulative incidence of thrombotic complications in critically ill ICU patients with COVID-19: An updated analysis. Thromb. Res. 2020, 191, 148-150. [CrossRef]

12. Middeldorp, S.; Coppens, M.; van Haaps, T.F.; Foppen, M.; Vlaar, A.P.; Müller, M.C.A.; Bouman, C.C.S.; Beenen, L.F.M.; Kootte, R.S.; Heijmans, J.; et al. Incidence of venous thromboembolism in hospitalized patients with COVID-19. J. Thromb. Haemost. JTH 2020, 18, 1995-2002. [CrossRef]

13. Lodigiani, C.; Iapichino, G.; Carenzo, L.; Cecconi, M.; Ferrazzi, P.; Sebastian, T.; Kucher, N.; Studt, J.-D.; Sacco, C.; Bertuzzi, A.; et al. Venous and arterial thromboembolic complications in COVID-19 patients admitted to an academic hospital in Milan, Italy. Thromb. Res. 2020, 191, 9-14. [CrossRef]

14. Llitjos, J.-F.; Leclerc, M.; Chochois, C.; Monsallier, J.-M.; Ramakers, M.; Auvray, M.; Merouani, K. High incidence of venous thromboembolic events in anticoagulated severe COVID-19 patients. J. Thromb. Haemost. JTH 2020, 18, 1743-1746. [CrossRef]

15. INSPIRATION Investigators; Sadeghipour, P.; Talasaz, A.H.; Rashidi, F.; Sharif-Kashani, B.; Beigmohammadi, M.T.; Farrokhpour, M.; Sezavar, S.H.; Payandemehr, P.; Dabbagh, A.; et al. Effect of Intermediate-Dose vs Standard-Dose Prophylactic Anticoagulation on Thrombotic Events, Extracorporeal Membrane Oxygenation Treatment, or Mortality Among Patients With COVID-19 Admitted to the Intensive Care Unit: The INSPIRATION Randomized Clinical Trial. JAMA 2021, 325, 1620-1630. [CrossRef]

16. Malas, M.B.; Naazie, I.N.; Elsayed, N.; Mathlouthi, A.; Marmor, R.; Clary, B. Thromboembolism risk of COVID-19 is high and associated with a higher risk of mortality: A systematic review and meta-analysis. EClinicalMedicine 2020, 29. [CrossRef]

17. Cuker, A.; Tseng, E.K.; Nieuwlaat, R.; Angchaisuksiri, P.; Blair, C.; Dane, K.; Davila, J.; DeSancho, M.T.; Diuguid, D.; Griffin, D.O.; et al. American Society of Hematology 2021 guidelines on the use of anticoagulation for thromboprophylaxis in patients with COVID-19. Blood Adv. 2021, 5, 872-888. [CrossRef]

18. Zarychanski, R.; ATTACC Investigators. Therapeutic Anticoagulation in Critically Ill Patients with Covid-19—Preliminary Report. medRxiv 2021. [CrossRef] 
19. Neal, M. A Multicenter, Adaptive, Randomized Controlled Platform Trial of the Safety and Efficacy of Antithrombotic Strategies in Hospitalized Adults with COVID-19. 2021. Available online: https:/ / clinicaltrials.gov/ct2/show /NCT04505774 (accessed on 29 July 2021).

20. University of Manitoba. Antithrombotic Therapy to Ameliorate Complications of COVID-19 (ATTACC), in Collaboration with Accelerating COVID-19 Therapeutic Interventions and Vaccines (ACTIV-4). 2021. Available online: https://clinicaltrials.gov/ct2 / show / NCT04372589 (accessed on 29 July 2021).

21. Allegheny Health Network. Wikipedia. 2020. Available online: https://en.wikipedia.org/w/index.php?title=Allegheny_Health_ Network\&oldid=964656458 (accessed on 5 July 2021).

22. Coronavirus Response. Allegheny Health Network. Available online: https://www.ahn.org/coronavirus.html (accessed on 5 July 2020).

23. Boden, S. Allegheny Health Network Starts Drive-Through Testing for COVID-19. Available online: https://www.wesa.fm/ post/allegheny-health-network-starts-drive-through-testing-covid-19 (accessed on 5 July 2020).

24. Schulman, S.; Kearon, C. Subcommittee on Control of Anticoagulation of the Scientific and Standardization Committee of the International Society on Thrombosis and Haemostasis Definition of major bleeding in clinical investigations of antihemostatic medicinal products in non-surgical patients. J. Thromb. Haemost. JTH 2005, 3, 692-694. [CrossRef]

25. Gómez-Mesa, J.E.; Galindo-Coral, S.; Montes, M.C.; Muñoz Martin, A.J. Thrombosis and Coagulopathy in COVID-19. Curr. Probl. Cardiol. 2021, 46, 100742. [CrossRef]

26. Zhou, F.; Yu, T.; Du, R.; Fan, G.; Liu, Y.; Liu, Z.; Xiang, J.; Wang, Y.; Song, B.; Gu, X.; et al. Clinical course and risk factors for mortality of adult inpatients with COVID-19 in Wuhan, China: A retrospective cohort study. Lancet Lond. Engl. 2020, 395, 1054-1062. [CrossRef]

27. Smilowitz, N.R.; Subashchandran, V.; Yuriditsky, E.; Horowitz, J.M.; Reynolds, H.R.; Hochman, J.S.; Berger, J.S. Thrombosis in hospitalized patients with viral respiratory infections versus COVID-19. Am. Heart J. 2021, 231, 93-95. [CrossRef]

28. Bunce, P.E.; High, S.M.; Nadjafi, M.; Stanley, K.; Liles, W.C.; Christian, M.D. Pandemic H1N1 influenza infection and vascular thrombosis. Clin. Infect. Dis. 2011, 52, e14-e17. [CrossRef]

29. Lim, W.; Meade, M.; Lauzier, F.; Zarychanski, R.; Mehta, S.; Lamontagne, F.; Dodek, P.; McIntyre, L.; Hall, R.; Heels-Ansdell, D.; et al. Failure of anticoagulant thromboprophylaxis: Risk factors in medical-surgical critically ill patients. Crit. Care Med. 2015, 43, 401-410. [CrossRef]

30. Piscoya, A.; Ng-Sueng, L.F.; del Riego, A.P.; Cerna-Viacava, R.; Pasupuleti, V.; Roman, Y.M.; Thota, P.; White, C.M.; Hernandez, A.V. Efficacy and harms of remdesivir for the treatment of COVID-19: A systematic review and meta-analysis. PLoS ONE 2020, 15, e0243705. [CrossRef]

31. Sanfilippo, F.; La Rosa, V.; Oliveri, F.; Astuto, M. Convalescent plasma for COVID-19: The risk of pulmonary embolism should not be underestimated! Crit. Care 2020, 24, 531. [CrossRef]

32. Lynn, L.; Reyes, J.A.; Hawkins, K.; Panda, A.; Linville, L.; Aldhahri, W.; Kango, G.; Shah, S.; Ayanian, S.; Teufel, K. The effect of anticoagulation on clinical outcomes in novel Coronavirus (COVID-19) pneumonia in a U.S. cohort. Thromb. Res. 2021, 197, 65-68. [CrossRef]

33. Godier, A.; Clausse, D.; Meslin, S.; Bazine, M.; Lang, E.; Huche, F.; Cholley, B.; Hamada, S.R. Major bleeding complications in critically ill patients with COVID-19 pneumonia. J. Thromb. Thrombolysis 2021, 52, 18-21. [CrossRef]

34. Rentsch, C.T.; Beckman, J.A.; Tomlinson, L.; Gellad, W.F.; Alcorn, C.; Kidwai-Khan, F.; Skanderson, M.; Brittain, E.; King, J.T.; Ho, Y.-L.; et al. Early initiation of prophylactic anticoagulation for prevention of coronavirus disease 2019 mortality in patients admitted to hospital in the United States: Cohort study. BMJ 2021, 372, n311. [CrossRef]

35. The REMAP-CAP Investigators; The ACTIV-4a Investigators; The ATTACC Investigators. Therapeutic Anticoagulation with Heparin in Critically Ill Patients with Covid-19. N. Engl. J. Med. 2021, NEJMoa2103417. [CrossRef]

36. NEJM. Therapeutic Anticoagulation with Heparin in Noncritically Ill Patients with Covid-19. Available online: https://www. nejm.org/doi/full/10.1056/NEJMoa2105911 (accessed on 1 November 2021).

37. Ten Cate, H. Surviving Covid-19 with Heparin? N. Engl. J. Med. 2021, 385, 845-846. [CrossRef] [PubMed] 